\title{
Morphological classification and treatment outcomes of children with AML during four years
}

By

\begin{abstract}
Pediatrics specialist Dr. Munaf Authman Hreeth ${ }^{* 1}$; Pediatrics specialist Dr. Ahmed Nadher Kareem ${ }^{* 2}$; Pediatrics specialist Dr. Sabah Noori Rashid ${ }^{* 3}$

${ }^{* 1}$ M.B.Ch.B, FIBMS Pediatrics, Speciality of general Pediatrics and neonatalogy Iraqi board and subspecialty of hematology in Pediatrics Iraqi board / Pediatric central teaching hospital/ Al-karch Health Directorate/ Ministry of Health and environment ; ${ }^{* 2,3}$ MB.Ch.B. ,D.C.H.,C.A.B.P Consultant pediatrician, Speciality of general Pediatrics and neonatology Iraqi board and subspecialty of hematology in

Pediatrics Iraqi board / Pediatric central teaching hospital / Al-karch Health Directorate/ Ministry of Health and environment / Baghdad / Iraq
\end{abstract}

D.O.I - $10.51201 / J U S S T / 21 / 05169$

http://doi.org/10.51201/JUSST/21/05169

\begin{abstract}
Acute myeloid leukemia comprises only $15 \%$ to $20 \%$ of acute leukemia in children. It remains a challenging disease with an inferior treatment outcome in comparison with acute lymphoblastic leukaemia (ALL).

This study aimed to document the morphological classification and treatment outcomes of children with Acute Myeloid Leukemia treated in the Child's Central Teaching Hospital (CCTH) in Baghdad / Iraq.

This retrospective study was conducted at CCTH in Baghdad, during the period from $1^{\text {st }}$ January 2009 to $31^{\text {st }}$ December 2012 on 49 cases who were diagnosed as AML. Down syndrome (DS) and acute promyelocytic leukemia (APL), with undifferentiated leukemia were excluded from this study.

The average age of presentation was 5 years, and the median duration of symptoms was 4 weeks, with male $(\mathrm{M})$ : female $(\mathrm{F})$ ratio $=1.13: 1$. It can be concluded that there was slight male predominance. The most common French-American-British (FAB) subtype was M2 38.8\%. From the total number of patients who received treatment $n=$ $38 / 49$ (77.5\%), death rate was $n=27 / 38(71 \%)$, the main cause of death was infection followed by bleeding, while lost to follow-up (during any period after started treatment) was $n=6 / 38(16 \%)$. Only five $\{n=5 / 38(13 \%)\}$ patients were still alive to the end of the study and those are in continuous complete remission one (CCR1).
\end{abstract}


It can be concluded that AML-M2 was the most common subtype, and the overall survival was much low and seems to be unlikely to increase without good supportive care and using of more intensification therapy.

Key words: AML, children, morphological classification, Treatment outcomes

\section{Introduction}

Acute myeloid leukemia (AML, also known as acute myelogenous leukemia) consists of a group of relatively well-defined hematopoietic neoplasms involving precursor cells committed to the myeloid line of cellular development (i.e. those giving rise to granulocytic, monocytic, erythroid or megakaryocytic elements). AML is characterized by a clonal proliferation of myeloid precursors with a reduced capacity to differentiate into more mature cellular elements. As a result, there is an accumulation of leukemic blasts or immature forms in the bone marrow, peripheral blood and occasionally in other tissues, with a variable reduction in the production of normal red blood cells, platelets and mature granulocytes [1,2]. Approximately 35\% of all childhood cancers are acute leukemias, of which $15-20 \%$ is AMLs \& most of others are acute (ALLs). In contrast to cure rates for ALL, those for AML have improved only moderately over the past few decades [3].

In1976, the FAB group proposed systems of AML based are specific morphologic, histochemical, \&, more recently, immunophenotypic \& cytogentic features. The system includes seven subtypes (M1 to M7) [4].

By using a large panel of monoclonal antibodies to myeloid \& lymphoid lineage \& progenitor cell associated antigen has been used to correctly discriminate myeloid or lymphoid differentiation in up to $98 \%$ of patients [5].

\section{Patients and methods}

The current retrospective study carried out in Pediatric Hemato-oncology unit in the Child's Central Teaching Hospital, Baghdad/Iraq included patients who were diagnosed during the period from $1^{\text {st }}$ January 2009 to $31^{\text {st }}$ December 2012 on 49 AML patients. Down syndrome and APL with undifferentiated leukaemia were excluded from this study.

The medical records of those children during the considered period were reviewed.

The patient's follow-up was taken from the record's file of the patient of the Hemato-oncology consultation clinic. 
Information recording (file No., gender, residence, date of diagnosis, date of starting treatment, presenting symptoms \& signs, duration of illness before diagnosis, initial finding of investigation, remission state, complications \& outcome) were also collected.

For hematological investigations, venous blood samples were taken by means of disposable syringes and put in tubes containing EDTA to estimate ( $\mathrm{Hb} \%$, WBC count and platelets counts).

The diagnosis of AML was established by clinical finding, CBC \& Morphological examination of BMA only because immunophenotyping and cytogenetic studies were unavailable.

Lumber puncture for CSF cytology and cytospin were done for assessment CNS status of patients, it's negative when there is no blast cells in CSF cytology and positive if there is identifiable blast cells.

All Patients with AML were treated with induction chemotherapy regimen modified from Medical Research council, United Kingdom, MRC-AML trial15.

For those who completed their treatment, follow-up examination \& investigations were scheduled for routine follow-up, monthly for $1^{\text {st }} 6$ months, then every 2 months for another 6 months, then every 3 months.

The event free survival (EFS); defined as any events \{early death, relapse, secondary malignancy, or death resulting from any cause \}and calculated from date of diagnosis to last follow-up or first event, while the overall survival (OS) was calculated from date of diagnosis to death [6].

\section{Statistical analysis}

The SPSS version 12 was used for data analysis. Chi-square test was used to identify the associations between the event free survival and studied independent variables, qualitative data were expressed as frequency and percentage, quantitative data as mean and median, P-values equal or less than 0.05 were considered significant.

\section{Results}

Results in our study showed that the age range between (0.3-13) years, with mean age at diagnosis was 5 years. Among 49 patients with AML, there were 26 (53\%) males and 23 female (47\%) with a male:female ratio 1.13:1. The duration of onset before diagnosis was in the range between 3 days to 6 months, and the median duration of symptoms was 4 weeks as shown in table (1).

Table (1) Age and gender distribution among AML patients 


\begin{tabular}{|l|l|l|}
\hline \multicolumn{1}{|c|}{ Patients characters } & \multicolumn{2}{c|}{ No. } \\
\hline Age (years) & \multicolumn{2}{|c|}{} \\
\hline$<2$ & 10 & 20.4 \\
\hline $2-9$ & 29 & 59.2 \\
\hline$\geq 9$ & 29 & 20.4 \\
\hline Gender & 10 & \multicolumn{2}{|c|}{} \\
\hline Male & \multicolumn{2}{|c|}{53} \\
\hline Female & 26 & 47 \\
\hline
\end{tabular}

FAB-M2 subtype was the most common type \& was diagnosed in 19 (38.8\%) patients, followed by M5 subtype in 11 (22.5\%) as shown in table (2).

Table (2): Morphological classification of AML

\begin{tabular}{|l|lc|}
\hline FAB Subtype & No. & \% \\
\hline M1 & 5 & 10.3 \\
\hline M2 & \multicolumn{1}{|l|}{} \\
\hline M4 & 9 & 38.8 \\
\hline M5 & & \\
\hline M6 & 11 & 22.5 \\
\hline M7 & 3 & 6.1 \\
\hline Total & & \\
& 2 & \\
\hline
\end{tabular}

Out of 49 patients, 11 (22.5\%) were excluded from the study (4 patients who died before receiving chemotherapy and 7 whose families refused treatment). 
The remaining $38(77.5 \%)$ patients received treatment according to Medical Research Council AML trial 15.

Of the 38 patients, 14 (36\%) did not complete induction (13 patients who died and one patient lost to follow- up). Patient who completed induction and got CR1 were 24 (64\%) patients.

Out of the 24 patients, 5 (20.8\%) got contentious complete remission, and 9 (37.5\%) died, while 8 (33.3\%) relapsed and 2 (8.4\%) lost to follow-up.

Of the total number of patients 38(77.5\%) who received treatment, 27 (71\%) died and $5(13 \%)$ were still alive, while $6(16 \%)$ of them lost to follow-up as seen in table (3).

The two year EFS for the treated patients was 7 (18.4\%) as shown in figure (1), while the two year OS was 10 (20.4\%) as shown in figure (2).

Table (3): Outcomes of AML

\begin{tabular}{|l|c|c|}
\hline & No. (49) & $\%$ \\
\hline Patients received treatment & 38 & 77.5 \\
\hline Patients not received treatment & 11 & 22.5 \\
\hline Not received treatment & 11 & \\
\hline Lost & 7 & 63.6 \\
\hline Died & 4 & 36.4 \\
\hline Patients not completed induction & 14 & 36.8 \\
\hline Died & 13 & 92.8 \\
\hline Lost to follow-up & 1 & 7.2 \\
\hline Patients completed induction and got contentious remission 1 & 24 & 63.2 \\
\hline Post induction phase & 24 & \\
\hline Died & 9 & 37.5 \\
\hline Relapse* & 8 & 33.3 \\
\hline Contentious complete remission 1 & 5 & 20.8 \\
\hline Lost to follow-up & 2 & 8.4 \\
\hline Relapse & 8 & \\
\hline Lost to follow-up & 3 & 37.5 \\
\hline Died & 27 & 71 \\
\hline Died & 52.5 \\
\hline
\end{tabular}




\begin{tabular}{|l|c|c|}
\hline Still alive & 5 & 13 \\
\hline Lost to follow up & 6 & 16 \\
\hline
\end{tabular}

*5(6.25\%) patients died (3 died during reinduction and 2 died before starting reinduction), while 3(37\%) patients lost to follo-up and (2) patients received reinduction and got CCR2 and (1) patient received only one cycle.

\section{Discussion}

The current study showed slight male predominance of 1.13:1 which is similar to the two studies conducted in the Pakistan by Fadoo ${ }^{\mathrm{n}}$ [7] and Aga Khan [8] which showed an M/F ratio of (1.87:1), and (1.3:1) respectively. The study of Khattab TM from Saudi Arabia showed slight female predominance of (0.74:1) [9].

The median age of our study was 5 years (range 0.3 year-13years) similar to Khattab TM study from Saudi Arabia of Median age of 5 years (range 0.5 year -14 years) [9]. However, they were slightly less than Fadoo [7], and Aga Khan [8], Imamura [10] findings. Median age was 8.5 years (6months - 15 years), 8 years (7 month -14.5years), 7.6 years (range 3 months-16.2 years) respectively. This might depend on the size of the sample taken and the age limits in each center.

AML-M2 subtype was diagnosed in $\{n=19 / 49$ (38.8\%) $\}$ patients of total AML cases, which was the most common subtype in our study. This is slightly similar to Imamura study $\{n=54 / 146(37 \%)\}[10]$, and higher than that reported in Aga Khan study $\{n=3 / 23(13 \%)$ [8]. The later study showed that AML-M4 was the most common subtypes $\{\mathrm{n}=15 / 23(65 \%)\}$.

While the least common subtypes of our study was AML-M6 \& M7 \{n=3/49(6.1\%), $\mathrm{n}=2 / 49(4 \%)\}$ respectively, which is similar to Imamura study [10], which showed AML-M6 \&M7 was $\{n=5 / 146(3 \%), n=10 / 146(7 \%)\}$ respectively. This may reflect the different natures of the disease among Iraqi children.

From the total 49 AML patients, eleven $\{n=11 / 49(22.5 \%)\}$ patients did not receive treatment either due to be lost to follow up $\{n=7 / 11(63.6 \%)\}$ or died $\{\mathrm{n}=4 / 11(36.4 \%)\}$. The death rate before starting treatment was higher than Al-Janabi [11] $\{n=2 / 43(4.6 \%)\}$, and the other $38\{n=38 / 49(77.5 \%)\}$ patients were treated according to Medical Research Council AML trial 15 AML protocol. Failure of induction was seen in $\{n=14 / 38(36.8 \%)\}$, which was similar to Fadoo [7] $\{n=12 / 33$ 
(36.3\%)\}, but lower than Al-Janabi [11] was $\{n=22 / 41(53.66 \%)\}$, and higher than Imamura [10] $\{\mathrm{n}=28 / 146$ (19\%) $\}$, and this may be due to high percentage of early death during induction $\{\mathrm{n}=13 / 14$ (92.8\%) $\}$ because of poor and inadequate supportive care facilities.

Of the 38 patients who received treatment only 24 patients $\{n=24 / 38(63.2 \%)\}$ achieved CR, while in the study of Al-Janabi [11], it was $\{n=19 / 41(46.3 \%)\}$.

Of the 24 CR patients, five $\{n=5 / 24(20.8 \%)\}$ patient had CCR1, which was higher than Al-Janabi [11] $\{\mathrm{n}=11 / 9$ (5.2\%) $\}$ and very low when compared to the results of Imamura [10] $\{\mathrm{n}=140 / 146(95.5 \%)\}$ and other studies like Creutzig et al [12] (77\%) \&Yeh etal [13] (89\%) in Taiwan.

Relapse rate was $\{n=8 / 24(33.3 \%)$ in post induction phase which was very higher than Fadoo [7] who reported $\{\mathrm{n}=7 / 33(21 \%)\}$, and lower than Al-Janabi [11] who reported $\{n=12 / 19(63 \%)\}$ relapse rate after induction, which may reflect the shortage and inadequacy of supportive management.

Most of relapsed patients died (3 patients died during reinduction and 2 patients died before starting reinduction) $n=5 / 8(62.2 \%)$ and lost to be followed-up (received reinduction) were $n=3 / 8$ (37\%), while survivors to the end of study were (50\%), and this may be due to poor supportive care.

There were $\operatorname{six}\{n=6 / 38(16 \%)\}$ patients who lost follow-up which was higher than the findings of the study of Fadoo [7] with $\{n=4 / 33(12 \%)\}$ and the study of Aga Khan [8] with $\{n=8 / 23(8 \%)\}$ and lower than Al-Janabi [11] with $\{n=14 / 41(34.15 \%)\}$, probably due to difficulties in transporting, forced familial immigration and security problems during the study period.

\section{References}

1. Ward E, DeSantis C, Robbin A,et al. Childhood cancer, 2014. CA Cancer J Clin 2014; 64:83.

2. Ries LG, Smith MA, Gurney JG, et al. (eds). Cancer Incidence and Survival among Children and Adolescents: United States SEER Program 1975-1995, National Cancer Institute, SEER Program. NIH Pub. No. 99-4649. Bethesda, MD, 1999. 
3. Carolyn B, Karl H, Look A.Myeloid Leukemia, Myelodysplasia, and Myeloproliferative disease in Children. In: Nathan DG, Orkin S, Ginsburg D and Look AT (editors). Hematology of Infancy and Childhood. $6^{\text {th }}$ ed. Saunders, 2003, 27:1167-1218.

4. Todd RG, Robert JA. Acute Myelogenous Leukemia. In Pizzo PA, Poplack DG (editors): Principles \& Practice of Pediatric Oncology, $4^{\text {th }}$ Ed. Philadelphia, Lippincott Williams \& Wilkins, 2002; pp 545-589.

5. Creutzig U, Harbott J, Sperling C, et al. Clinical significance of surface antigen expression in children with AML: Results of study AML-BFM-87. Blood 1995; 86: 3097-3108.

6. Woods WG. Intensified Induction Therapy for Children with AML. Ann Hematol. 83 suppln 1, 2004:S119-S120.

7. Fadoo Z, Mushtaq N, Alvi S, Ali M. Acute myeloid leukaemia in children: experience at a tertiary care facility of Pakistan. JPMA - J Pakistan Med Assoc. 2012;62(February):125-8.

8. Medicine F. Acute Myeloid Leukemia in Children in Pakistan: an Audit. j.pak.med.assoc. 6(46):141-9.

9. Khattab TM, Atra AA, Elimam NA, Kassar A, Zayed A, Baothman A. Improved outcome of children with acute myeloid leukemia treated on 2 consecutive protocols. saudi med j. 2008;59(5):7.

10. Imamura T, Iwamoto S, Kanai R, Shimada A, Terui K, Osugi Y, et al. Outcome in 146 patients with paediatric acute myeloid leukaemia treated according to the AML99 protocol in the period 2003-06 from the Japan Association of Childhood Leukaemia Study. Br J Haematol. 2012;159(2):204-10.

11.Al-Janabi-AN,Al-Ghabban-JM,Al-Shujair-TA,Al-Kubayasi-AI,Al-Shaibani

MR;some epidemiologic criteria and outcome of acute myelogenous leukemia in 
child's central teaching hospital;IMJ,June 2011,57(1):50-57.

12. Creutzig U, Zimmermann M, Lehrnbecher T, et al. Less Toxicity Optimizing Chemotherapy, but not by Addition of Granulocyte-Colony Stimulating Factor in Children and Adolescents with AML: Results of AML-BFM 98. J Clin Oncol 2006; 24: 4499-4506.

13. Yeh TC, Lin HC, Wang LY, et al. the development of a novel protocol for the treatment of de novo childhood acute myeloid leukemia in a single institution in Taiwan. J Pediatr Hematol Oncol 2007 Dec; 29(12):826-831. 